\title{
Obstáculos Emergentes da Prática de Ensino com a Investigação Matemática
}

\author{
Emerging Obstacles of Teaching Practice with Mathematical Research
}

\begin{abstract}
Resumo
Da perspectiva qualitativa fenomenológica-hermenêutica, interrogo, neste artigo, os fatores que se mostraram limitantes do trabalho com a Investigação Matemática a partir do relatado nas produções de professores que trabalharam sob essa perspectiva no Programa de Desenvolvimento Educacional do Paraná (PDE). O movimento de pesquisa realizado é o da percepção como uma experiência consciente, exemplificada pela metáfora do cubo de Sokolowski. Articulados em quatro categorias, os dados permitem afirmar que os obstáculos são decorrentes das ações dos sujeitos envolvidos no trabalho (professores e alunos), da dinâmica e características epistemológicas da própria Investigação Matemática, da estrutura e organização escolar e da inserção das Tecnologias da Informação e Comunicação (TIC) e encontram explicações nas concepções e crenças próprias dos professores, dos alunos, da gestão escolar, da equipe pedagógica, da família e do Estado, advindas da cultura escolar predominante.
\end{abstract}

Palavras-chave: Fenomenologia. Investigação Matemática. Obstáculos. Prática Pedagógica.

\begin{abstract}
From the qualitative-phenomenological-hermeneutic perspective, we researched in this article, the factors that limited the Mathematical Research task, as reported in the productions of teachers who worked under this perspective in the Educational Development Program of Paraná (EDP). The research movement is that of perception as a conscious experience, exemplified by Sokolowski's cube metaphor. We articulated the data in four categories to be able to affirm that the obstacles stem from the actions of the subjects involved in the work (teachers and students), from the dynamics and epistemological characteristics of Mathematical Research itself, from the school's structure and organization, and from the insertion of the Information and Communication Technologies (ICT), which find more explanations in the conceptions and beliefs of teachers, students, school management, pedagogical team, family, and state, coming from the prevailing culture.
\end{abstract}

Keywords: Phenomenology. Mathematical Research. Obstacles. Pedagogical Practice.

\section{Situando e justificando a pesquisa}

A existência de metodologias não tradicionais para o ensino da Matemática tem sugerido mudanças nas práticas docentes e discentes, implicando, diretamente, no modo de ensinar e aprender. A escola, enquanto parte do processo educativo, é imediatamente alcançada pelos

\footnotetext{
* Doutorando em Educação em Ciências e Educação Matemática (UNIOESTE). Professor colaborador do Departamento de Engenharias e Exatas (UFPR), Palotina, Paraná, Brasil. Endereço para correspondência: Rua Padre Cirilo, 3033, São Cristóvão, Capanema, Paraná, Brasil, CEP: 85760-000. E-mail: wichnoski@gmail.com.
} 
novos paradigmas e, em tese, também tende a se modificar. Mudanças sugerem adequações, alterações, transições, que, por sua vez, sugerem a existência de problemas. Nesse sentido, a inserção de diferentes metodologias para o ensino da Matemática requer adaptações e, mais do que isso, requer mudança nos modos de pensar, agir e organizar o sistema educativo como um todo. Por consequência, se desencadeia uma série de problemas e desafios refletidos, diretamente, na prática de ensino, o que tem despertado o interesse dos pesquisadores nos diversos domínios da Educação Matemática, conforme nos diz Cunha (2000, p. 1):

Num contexto de mudança e de inovações curriculares colocam-se desafios ao professor, aos alunos e aos investigadores. Assim, uma área de interesse relativamente recente da investigação em educação matemática surgiu em torno dos dilemas e das dificuldades que os professores enfrentam nas suas aulas, particularmente quando são confrontados com mudanças ao nível das metodologias a implementar e das tarefas que necessitam realizar.

A exemplo, podem ser citados os trabalhos de Pereira (2013), que enfoca as dificuldades e limitações que o professor encontra ao buscar uma formação amparada na História da Matemática; de Ceolim e Caldeira (2017), que discutem os obstáculos e dificuldades de professores em aulas de Modelagem Matemática; e de Siltrão e Cristovão (2010), que se debruçam sobre as dificuldades enfrentadas por uma professora em aulas de Investigação Matemática.

Particularizando a Investigação Matemática, informa-se que essa tem sido o foco principal dos estudos por mim engendrados e, ao interrogá-la constantemente, outras possibilidades de compreensão vão se abrindo e novas reflexões se estabelecem. Um desses estudos, que serviu de ensejo para este trabalho, é a minha pesquisa ${ }^{1}$ de mestrado que, sob a via da fenomenologia-hermenêutica, buscou uma metacompreensão dos manifestos da Investigação Matemática nas produções (produção didático-pedagógica ${ }^{2}$ e artigo final ${ }^{3}$ ) de professores que trabalharam sob essa perspectiva no Programa de Desenvolvimento Educacional do Estado do Paraná (PDE) ${ }^{4}$.

\footnotetext{
${ }^{1}$ Pesquisa financiada pela Coordenação de Aperfeiçoamento de Pessoal de Ensino Superior (CAPES) e intitulada "Uma Metacompreensão da Investigação Matemática nas Produções do Programa de Desenvolvimento Educacional do Paraná - PDE”.

2 Trata-se da organização de um material didático, contendo uma estratégia metodológica, tendo por finalidade a implementação na escola.

${ }^{3}$ Texto que divulga e socializa o trabalho desenvolvido na escola, contemplando a problemática estudada, os dados coletados na implementação da Produção Didático-pedagógica e a respectiva análise.

${ }^{4}$ Programa de Capacitação Continuada do estado do Paraná, implantado como uma política educacional de caráter permanente, que prevê o ingresso anual de professores da Rede Pública Estadual de Ensino para a participação em processo de formação continuada com duração de 2 (dois) anos, tendo como meta qualitativa a melhoria do processo de ensino e aprendizagem nas escolas públicas estaduais de Educação Básica (PARANÁ, 2010). Em linhas gerais, o PDE se organiza e se desenvolve assentado em diversas atividades teórico-práticas, de modo articulado. Tais atividades contemplam orientações entre os professores participantes e os professores formadores,
} 
Dentre os aspectos revelados pela pesquisa supracitada, manifestaram-se dificuldades, desafios e dilemas que podem ter sido limitantes das práticas empreendidas e, com algum grau de generalidade, da inserção dessa metodologia na sala de aula. Na época do desenvolvimento da referida pesquisa, tais aspectos não foram esmiuçados e desvelados em sua totalidade, uma vez que o objetivo era buscar pela manifestação da Investigação Matemática e não pela manifestação dos problemas e das dificuldades emergentes do trabalho investigativo. Entretanto, eles foram cointencionados e, ao refletir sobre o trabalho realizado e retomar as mesmas obras, se abrem à investigação.

Em face disso, bem como pelo próprio itinerário e movimento de pesquisador afeto à Investigação Matemática, senti a necessidade de retornar às mesmas obras consideradas na pesquisa de mestrado, mais precisamente aos artigos finais, e interrogar os fatores que se mostraram contrários às práticas empreendidas. De uma postura fenomenológica, persigo este objetivo com a seguinte interrogação: Quais obstáculos se mostraram limitantes da prática com a Investigação Matemática segundo o relatado nas produções de professores que trabalharam sob essa perspectiva no PDE/PR?

Desse modo, o retorno dá-se às mesmas obras, porém o olhar inquiridor vê, persegue e interroga o fenômeno sob outra perspectiva, o que é possível quando se trabalha fenomenologicamente. O movimento realizado é o da percepção como uma experiência consciente, exemplificada pela metáfora do cubo de Sokolowski.

Segundo Sokolowski (2012), ao intencionarmos o olhar para um cubo, o percebemos em partes. Não é possível que o cubo, em seu todo, seja visto no campo da visão do observador. Contudo, ao ver as partes que se mostram visíveis, as partes presentemente invisíveis são intencionadas e cointencionadas. Nesse sentido, experienciamos os lados do cubo potencialmente visíveis e aqueles potencialmente invisíveis, porém cointencionados. Esta estrutura de percepção é formulada em dimensões objetivas e subjetivas.

\footnotetext{
Objetivamente, o que nos é dado quando vemos um cubo é uma mistura composta dos lados que estão presentes e dos lados que estão ausentes, mas cointencionados. A coisa sendo vista envolve uma mistura do presente e do ausente. Subjetivamente, nossa percepção, nossa visualização, é uma mistura composta de intenções cheias e vazias. Nossa atividade de perceber, então, também é uma mistura; partes intencionam o que está presente, e outras partes intencionam o que está ausente, os “outros lados” do cubo (SOKOLOWSKI, 2012, p. 25-26).
}

\footnotetext{
a elaboração e implementação de um projeto de intervenção pedagógica em escolas públicas da rede estadual de ensino, a construção de uma produção didático-pedagógica e a construção de um trabalho/artigo final. No projeto de intervenção constam as táticas, as ações planejadas ao longo do processo e que serão desenvolvidas na escola. Tal planejamento é sistematizado na produção didático-pedagógica, a qual contém as estratégias metodológicas que atendam aos propósitos do projeto de intervenção e, por fim, o trabalho final corresponde a um artigo científico e tem o objetivo de divulgar e socializar o trabalho desenvolvido.
} 
À vista disso, compreendo que, ao intencionar, na pesquisa de mestrado, a Investigação Matemática em sentido lato (o cubo), os problemas e as dificuldades emergentes do trabalho investigativo (faces ou partes do cubo) foram cointencionados, isto é, foram percebidos como intenções vazias, potencialmente visíveis, mas realmente ausentes, fora campo de visão determinado naquele momento pela perspectiva do meu olhar.

Todavia, segundo Sokolowski (2012), as intenções vazias, as partes potencialmente visíveis, também são parte do que experienciamos e podem ser iluminadas, tornando-se intenções cheias na medida em que são percebidas de outra perspectiva. Segundo o autor supracitado:

\begin{abstract}
Nossa percepção é dinâmica, não estática; até se só olharmos um lado do cubo, o movimento rápido dos nossos olhos introduz um tipo de mobilidade de busca da qual não estamos conscientes. Quando viramos um cubo ou caminhamos em volta dele, a potencialidade percebida torna-se realmente percebida, e o realmente percebido desliza para dentro da ausência; torna-se aquilo que foi visto, aquilo que é novamente só potencialmente visto. No lado subjetivo, as intenções vazias tornam-se cheias e as cheias tornam-se vazias (SOKOLOWSKI, 2012, p. 26).
\end{abstract}

Assim sendo, conforme caminho em volta do fenômeno interrogado na pesquisa de mestrado (a Investigação Matemática/o cubo), os problemas e as dificuldades com o trabalho investigativo tornam-se percebidos e tendem a ser iluminados; é a intenção vazia que, na subjetividade do pesquisador, torna-se cheia, possibilitando a experiência com a Investigação Matemática sob um outro ângulo.

Para Sokolowski (2012, p. 28), "é essencial para a nossa experiência que percebamos toda essa multiplicidade como pertencendo a um e ao mesmo cubo". Destarte, perceber outro aspecto da Investigação Matemática é essencial para a minha experiência com ela, enquanto pesquisador afeto. Desse modo, como um movimento de pesquisa subjetivo, o trabalho se justifica.

Sem ingenuidades, qualquer que seja o processo de transformação haverá problemas e desencontros que, por vezes, não serão extinguidos em sua totalidade, porém é possível minimizá-los na medida em que são identificados, juntamente às suas causas. Nesse sentido, é importante olhá-los não como problemas, mas como complexidades que querem nos dizer algo, que denunciam distorções, desencontros e que indicam possibilidades de serem solucionados e, para isso, é preciso antes conhecê-los.

Assim, o trabalho se justifica na dimensão intersubjetiva, porque busca contribuir com o ensino de Matemática pautado na perspectiva da Investigação Matemática ao revelar problemas enfrentados em situações práticas e que, com algum esforço de pesquisa, podem ser contornados. 
Ao tematizar a Investigação Matemática situada na Educação Matemática, compreendoa na acepção de Ponte, Brocardo e Oliveira (2013) como uma atividade que está no cerne da produção do conhecimento em Matemática e que, em contextos de ensino e aprendizagem, possui relações com o fazer Matemática por meio de tarefas abertas, situadas em contextos variados, embora com predominância para os exclusivamente matemáticos.

Desse prelúdio, na próxima seção, passo a discorrer sobre os aspectos metodológicos, seguida das seções que explicitam o revelado pelos dados da pesquisa, caminhando em direção a uma articulação do revelado, como desfecho do trabalho.

\section{Explicitando os aspectos metodológicos}

O trabalho se assenta na metodologia qualitativa como uma pesquisa social e historicamente situada, buscando pelo sentido e significado do interrogado. Com isso, esse estudo não busca a mensuração dos resultados, mas uma interpretação, reflexiva e subjetiva, sob a via de um processo indutivo. Portanto, a pesquisa preocupa-se

[...] com um nível de realidade que não pode ser quantificado. Ou seja, ela trabalha com o universo de significados, motivos, aspirações, crenças, valores e atitudes, o que corresponde a um espaço mais profundo das relações, dos processos e dos fenômenos que não podem ser reduzidos à operacionalização de variáveis (MINAYO, 2001, p. 21-22).

Dentre os diversos modos de se pesquisar qualitativamente, foi assumida a abordagem fenomenológica, uma vez que o olhar do pesquisador se dirige ao interrogado como um fenômeno e não como um fato, enquanto realidade objetiva. É, portanto, uma atitude em que me percebo como pesquisador e percebo a realidade que me cerca em termos de possibilidades e não de objetividades, conforme sugerem Martins e Bicudo (1989). Ao dizer que o interrogado é visto como um fenômeno, significa que ele se revela a quem interroga e, portanto

[...] não se trata de um objeto objetivamente posto e dado no mundo exterior ao sujeito e que pode ser observado, manipulado, experimentado, medido, contado por um sujeito observador [...] mas é o que se mostra no ato de intuição efetuado por um sujeito individualmente contextualizado, que olha em direção ao que se mostra de modo atento e que percebe isso que se mostra nas modalidades pelas quais se dá a ver no próprio solo em que se destaca como figura de fundo (BICUDO, 2011, p. 30).

Em face disso, o trabalho ganha características de pesquisa qualitativa fenomenológica por assumir a busca pela compreensão do interrogado mediada pela intencionalidade e não explicações causais do mesmo. Portanto, o modo de pesquisar fenomenologicamente opõe-se à visão empirista que acredita em uma possibilidade do conhecimento exclusivamente derivada da experiência, dos fatos. Apresenta-se, pois, como um método original que se move do 
constituído (realidade concreta) ao constituinte (essências) que, por sua vez, contém a clareza, a inteligibilidade do constituído. Assim, ao mesmo que tempo que contesta as aparências empíricas, as explicam (BRUYNE; HERMAN; SCHOUTHEETE, 1977). Isso, segundo Husserl (2002), nos permite voltar às próprias coisas como se apresentam em sua pureza.

Ao interrogar quais fatores se mostram limitantes do trabalho com a Investigação Matemática, há uma intencionalidade de olhá-los como se mostram, na experiência explicitada nas produções dos professores que trabalharam sob essa perspectiva no PDE. É um dos lados do cubo sendo enfocado de modo atento e que se torna realmente percebido, doando-se "em aspectos passíveis de serem vistos na perspectiva daquele que a ele se dirige atentivamente" (BICUDO, 2011, p. 31). Desta postura e guiado pela interrogação de pesquisa, fui remetido ao solo de manifestação do fenômeno (os artigos finais) na busca de construir dados significativos que permitam responder ou iluminar a interrogação construída.

Ainda durante a construção da pesquisa de mestrado, esses artigos tornaram-se acessíveis no portal da Secretaria de Educação do governo do Paraná (SEED) ${ }^{5}$, por meio de uma busca sistematizada utilizando os descritores Investigação Matemática e Investigações Matemáticas. Os artigos trazem, em seu conteúdo, o relato e reflexões sobre práticas de ensino pautadas na Investigação Matemática e empreendidas na Educação Básica Pública do Estado do Paraná.

Considerando os diferentes níveis em que se organiza a Educação Básica brasileira, as práticas relatadas foram empreendidas nos Anos Finais do Ensino Fundamental, sendo sete práticas em turmas do $6^{\circ}$ ano, três em turmas do $7^{\circ}$ ano, quatro em turmas do $8^{\circ}$ ano e oito em turmas do $9^{\circ}$ ano. No Ensino Médio, foram empreendidas quatro práticas no $1^{\circ}$ ano, uma prática no $2^{\circ}$ ano, uma no $3^{\circ}$ ano do Ensino Médio regular e uma no $3^{\circ}$ ano do Magistério. Na modalidade de Educação de Jovens e Adultos, doravante EJA, houve uma prática empreendida. Outros três artigos relataram práticas empreendidas em cursos de formação de professores de Matemática. Dentre esses trabalhos, quinze relataram a utilização das TIC. O Quadro 6 (em anexo) traz a identificação de cada artigo, bem como o link para o acesso.

Após a leitura da totalidade dessas produções, que, em termos quantitativos, perfazem um universo de 33 (trinta e três) artigos, busquei colocar em evidência sentenças relevantes a minha miragem e que explicitaram algum sentido ante o interrogado, ou seja, as falas dos sujeitos que se destacaram ao meu olhar e se mostraram significativas mediante a interrogação norteadora do trabalho. Tais sentenças são aqui denominadas, tal como Bicudo (2011), de

\footnotetext{
${ }^{5}$ http://www.diaadia.pr.gov.br/
} 
unidades de sentido. Com a intenção de transformá-las em sentenças articuladas com o campo de inquérito constituído perante o objetivo do estudo, procedi a interpretação e reflexão sobre o dito, construindo as unidades de significado. Este momento é exemplificado no Quadro 1.

\begin{tabular}{|l|l|}
\hline \multicolumn{1}{|c|}{ Unidades de sentido } & \multicolumn{1}{|c|}{ Unidades de significado } \\
\hline $\begin{array}{l}\text { Percebeu-se que além da dificuldade de interpretação, os } \\
\text { alunos, em geral, não conseguem escrever suas } \\
\text { conclusões. }\end{array}$ & $\begin{array}{l}\text { A interpretação da tarefa e a escrita do relatório se } \\
\text { colocam como fatores que atravancam a prática com } \\
\text { a Investigação Matemática. }\end{array}$ \\
\hline $\begin{array}{l}\text { A realização de trabalho em grupo efetivamente } \\
\text { produtivo e com envolvimento necessário de seus } \\
\text { participantes. }\end{array}$ & $\begin{array}{l}\text { A falta de envolvimento dos alunos é um dos fatores } \\
\text { limitantes da prática com a Investigação } \\
\text { Matemática. }\end{array}$ \\
\hline $\begin{array}{l}\text { Posso estar enganada, mas acredito que essa } \\
\text { modalidade: investigações matemáticas, deve ser } \\
\text { aplicada esporadicamente, pois temos um currículo } \\
\text { muito extenso para ser cumprido e parece que esse tipo } \\
\text { de trabalho leva mais tempo para ser desenvolvido com } \\
\text { os alunos do que o método tradicional. }\end{array}$ & $\begin{array}{l}\text { Aorganização do currículo o o tempo são fatores que } \\
\text { atravancam a prática com a Investigação } \\
\text { Matemática. }\end{array}$ \\
\hline
\end{tabular}

Quadro 1 - Exemplos de unidades de sentido e respectivas unidades de significado Fonte: Elaborado pelo autor (2019)

Ao retomar a leitura, agora incidindo sobre as unidades de significado, procedi à redução fenomenológica de modo a agrupá-las sob algum aspecto comum. Em um movimento interpretativo e de busca pela compreensão do interrogado, efetuei as primeiras convergências, as quais deram origem às primeiras ideias nucleares. Ao serem retomadas à luz da pergunta diretriz, ainda se mostraram convergentes e solicitaram novas convergências, originando, assim, as segundas ideias nucleares.

Desse proceder foi possível, após duas reduções fenomenológicas, a construção das categorias de análise, entendidas como convergências de sentidos percebidos pelo pesquisador e que articulam as características globais expressas em cada unidade de significado (BICUDO, 2011). Nomeadamente as categorias de análise são: $C_{1}-$ Obstáculos relacionados aos sujeitos envolvidos no trabalho com a Investigação Matemática, $\mathrm{C}_{2}-$ Obstáculos intrínsecos à Investigação Matemática, $\mathrm{C}_{3}-$ Obstáculos advindos da estrutura escolar e $\mathrm{C}_{4}-$ Obstáculos advindos da inserção da TIC em aulas de Investigação Matemática, descritas e interpretadas em seção específica.

Embora, ao transcrever os movimentos realizados e expressá-los por meio da linguagem, haja certa impressão de linearidade, ressalto que eles foram enxertados de idas e vindas, de (re)começos, de (des)articulações e (in)certezas. Foram movimentos que se realizaram "efetuando insight, abstrações, comparações, articulações, reunindo e separando aspectos, expressando o compreendido pela linguagem, [...] enfim são movimentos do pensar ao percorrer os meandros do pensamento investigativo" (BICUDO, 2011, p. 59).

Da perspectiva fenomenológica, o percebido e articulado em cada uma das categorias encontra possibilidades de ser explicitado pela linguagem na experiência vivida pelo 
pesquisador, pois, como nos diz Husserl (2006, p. 161), a aspiração da Fenomenologia é a de "ser uma doutrina eidética descritiva dos vividos transcendentais puros". Desse modo, passo a descrever o revelado por cada categoria, expondo o vivido, sentido e percebido. Recorro à hermenêutica ${ }^{6}$ para compreender o apontado nas descrições e os sentidos expostos nas unidades de significado, transcendendo o individualmente relatado e avançando em direção à sua estrutura mais abrangente.

A descrição de cada categoria é antecedida de um quadro contendo algumas unidades de sentido e o respectivo discurso articulado do pesquisador sobre elas (unidades de significado), a fim de explicitar, em partes, o movimento interpretativo efetuado. Cada unidade de sentido foi codificada de acordo com o número do trabalho analisado e com a ordem de destacamento, por exemplo, o código (1.1) faz menção à unidade de sentido 1, destacada do artigo 1. Os códigos serão utilizados no decorrer da análise para referenciar as unidades de sentido que estão exemplificadas nos respectivos quadros que antecedem cada categoria. Aquelas não exemplificadas serão transcritas na íntegra, acompanhadas do código de identificação.

\section{A categoria $C_{1}$ - Obstáculos relacionados aos sujeitos envolvidos no trabalho com a investigação matemática}

\section{Unidades de sentido}

para mim esse método não foi legal, pois foi mais difícil de aprender, pois sou acostumada a decorar fórmulas, mas acho que tendo um pouco mais de paciência seria muito interessante. (13.9)

Um grande desafio para o professor de matemática é superar o descaso dos alunos com a disciplina. Vários fatores contribuem para a falta de motivação e o desinteresse de boa parte dos educandos (1.2)

As dificuldades também se devem ao fato de que esse tipo de tarefa exige deles o raciocínio, a interpretação e análise de situações desconhecidas que, geralmente, não são exploradas em sala de aula durante as aulas de matemática (21.2)

$\mathrm{Na}$ resolução das tarefas percebe-se a ausência de conhecimentos básicos, por isso existe uma grande dificuldade (16.2)

Uma das maiores dificuldades apresentadas foi quanto à interpretação da questão (30.1)

Na primeira atividade de investigação os alunos apresentaram muita resistência. O primeiro argumento dado pelos alunos é não saber o que pede o conteúdo, os alunos não conseguem interpretar o que se pede na tarefa (16.1)

\section{Unidades de significado}

O costume dos alunos com o trabalho tradicional foi causa de desgosto pela Investigação Matemática.

O descaso com a Matemática, por parte dos alunos, é um desafio nas aulas de Investigação Matemática.

O exercício da atividade matemática genuína, por parte dos alunos, foi uma dificuldade a ser superada no trabalho investigativo.

A falta de conhecimentos matemáticos dos alunos foi um problema para a prática investigativa.

A interpretação dos enunciados das tarefas foi uma dificuldade encontrada.

A resistência dos alunos à Investigação Matemática se justificou, em parte, pela incapacidade de interpretar os enunciados das tarefas.

${ }^{6}$ Cf. Mondini, Mocrosky e Bicudo (2016). 
Unidades de sentido

Outro obstáculo foi a rotatividade e a falta de assiduidade dos alunos durante a aplicação do projeto (11.7)

Outra constatação importante foi a necessidade de um bom preparo do professor para utilizar essa metodologia, uma vez que é fundamental que o trabalho seja desenvolvido pelos alunos e como eles não têm a prática de serem os protagonistas na sala de aula, pois em geral é o professor que exerce essa função, muitos ficavam ansiosos e pediam à professora que “explicasse" lá na frente (27.14)

Em relação às dificuldades na implementação ressalta-se o estranhamento dos alunos em trabalhar com investigações matemáticas, principalmente quanto à organização e o registro escrito dos resultados, de seus pensamentos e suas justificativas (11.5)

Quadro 2 - Algumas unidades de significado articuladas na categoria C1 Fonte: Elaborado pelo autor (2019)

Esta categoria revela os obstáculos relacionado aos sujeitos (professor e aluno) envolvidos nas práticas de ensino. É reveladora de aspectos que surgiram em face de concepções, comportamentos e características formativas desses sujeitos e que se caracterizam como dificuldades e impedimentos do trabalho com a Investigação Matemática. Um fator manifestado como obstáculo para a inserção dessa metodologia em sala de aula foi a insegurança sentida pelo professor, advinda da falta de clareza acerca dos aspectos epistemológicos e metodológicos que sustentam a Investigação Matemática e, de modo mais amplo, acerca de outras metodologias que se encontram nos documentos oficiais paranaenses, sendo: "Poucos os professores de matemática que estão preparados para utilizar as metodologias propostas nas diretrizes curriculares" (1.1).

O interesse e o efetivo envolvimento dos alunos na atividade são ações necessárias para o trabalho com a Investigação Matemática. Isso revelou outro fator limitante desse tipo de trabalho e que se destacou como uma das maiores dificuldades encontradas, a saber, a falta de clareza e entendimento do que vem a ser a realização de Investigações Matemáticas nas aulas de Matemática, por parte dos alunos, conforme o excerto: "Destaca-se que a maior dificuldade encontrada durante a realização das atividades foi fazer os alunos entenderem o processo de investigação, em que deveriam, a partir de seus conhecimentos prévios, buscar, desencadear as conjecturas e encontrar a possível solução para as atividades apresentadas" (27.13).

A necessidade de o aluno desempenhar e desenvolver habilidades da atividade matemática genuína como, por exemplo, raciocinar, interpretar e analisar situações desconhecidas, se mostraram motivos de objeção à Investigação Matemática (21.2). Este aspecto se revelou igualmente em práticas empreendidas em cursos de formação para professores "que se mostraram pouco à vontade nas investigações, querendo, prontamente, encontrar a solução, sem investigar" (6.1). 
A concepção dos alunos sobre a Matemática, sobre as aulas de Matemática, sobre o papel do professor, sobre o seu próprio papel (13.9) e a não habitualidade com o ensino pautado na Investigação Matemática fez com que houvesse indícios de insegurança, impaciência e resistência a esse tipo de trabalho, dificultando-o. Tais dificuldades podem ser "explicadas, talvez, pela falta de hábito de resolver exercícios através da investigação” (12.6). Devido a essa falta de experiência com a metodologia, os alunos sentiram-se desconcertados ao ter de trabalhar de forma autônoma, sem seguir uma direção previamente delimitada (16.1). Como consequência direta dessa não habitualidade, revelaram-se problemas de ordem técnica como, por exemplo, problemas com a escrita dos relatórios e com as próprias ações frente à atividade.

De igual modo, a não habitualidade com o ensino pautado na Investigação Matemática foi manifestada entre professores e se mostrou, também, impedimento da inserção desta metodologia nas aulas de Matemática. Segundo alguns professores que participaram do PDE, "se, por um lado, é interessante investigar, analisar possibilidades e chegar a uma conclusão que, nem sempre, foi a elaborada pelo autor da atividade, por outro lado, essa abertura de possibilidades pode levar professores inexperientes ou com menor domínio dos conteúdos, a evitarem o uso desse tipo de atividades na sala de aula" (12.10).

A aversão típica e o descaso em relação à disciplina de Matemática (1.2) tornaram-se grandes desafios para o professor. De igual modo, as dificuldades subjetivas com a disciplina e a falta de domínio de conteúdos matemáticos básicos (16.2), também se mostraram propulsores de problemas e de desistências do trabalho por parte dos alunos. As dificuldades impostas pelas tarefas, assim como a exigência do pensamento contínuo e intenso acabaram por fazer os alunos esmorecerem nas atividades, culminando em desinteresse e forçando o término da prática, conforme sugerem os seguintes excertos: "O nível de envolvimento foi grande, mas percebeuse até um desânimo, pois tiveram dificuldade, precisavam pensar muito, calcular e no final nem todos estavam interessados" (12.7) "e começaram a perder a motivação inicial, principalmente por necessitarem de raciocínio e concentração para encontrar regularidades e padrões" (27.3).

Além dos comportamentos de aversão, desinteresse e descaso com a Matemática, comportamentos relacionados à indisciplina, tais como agitação, conversa e falta de assiduidade atrapalharam o bom andamento das práticas com a Investigação Matemática, acarretando prejuízos (1.2) (11.7). 


\section{A categoria $C_{2}$ - Obstáculos intrínsecos à Investigação Matemática}

\section{Unidades de sentido}

Em relação às dificuldades na implementação ressalta-se o estranhamento dos alunos em trabalhar com investigações matemáticas, principalmente quanto à organização e o registro escrito dos resultados, de seus pensamentos e suas justificativas (11.5)

Percebeu-se que, além da dificuldade de interpretação, os alunos, em geral, não conseguem escrever suas conclusões (11.2)

"posso estar enganada, mas acredito que essa modalidade: investigações matemáticas, deve ser aplicada esporadicamente, pois temos um currículo muito extenso para ser cumprido e parece que esse tipo de trabalho leva mais tempo para ser desenvolvido com os alunos do que o método tradicional" (27.1) Para uma mesma atividade existem várias possibilidades de chegar a uma mesma conclusão, esse parece ser o maior obstáculo à implementação dessa metodologia para o ensino de matemática (12.8)

Se, por um lado, é interessante investigar, analisar possibilidades e chegar a uma conclusão que, nem sempre, foi a elaborada pelo autor da atividade, por outro lado, essa abertura de possibilidades pode levar professores inexperientes ou com menor domínio dos conteúdos, a evitarem o uso desse tipo de atividades na sala de aula (12.10)

\section{Unidades de significado}

O registro escrito é um aspecto que dificulta a inserção dessa metodologia em sala de aula.

A incapacidade de registrar as conclusões foi uma dificuldade encontrada.

O tempo requerido para a prática de Investigação Matemática é um fator desfavorável a sua inserção na escola.

As diversas possibilidades de explorar uma mesma tarefa de Investigação Matemática é um obstáculo às práticas investigativas.

A abertura das tarefas de Investigação Matemática é causa para os professores evitarem seu uso em sala de aula.

Quadro 3 - Algumas unidades de significado articuladas na categoria C2

Fonte: Elaborado pelo autor (2019)

A categoria é reveladora dos obstáculos que se originam a partir das características próprias da Investigação Matemática. São obstáculos que emergiram frente aos procedimentos da atividade investigativa, tais como: tempo, argumentação, justificação e escrita de relatórios.

A escrita dos relatórios em linguagem proposicional, contendo as hipóteses, as conjecturas, as justificativas e o processo de pensamento construído em face das tarefas, se mostrou uma dificuldade recorrente (11.5), bem como a utilização da linguagem matemática tanto para interpretar como para analisar e registrar os resultados (11.2). Os alunos mostraram ter pouca ou nenhuma habilidade para argumentar matematicamente os seus resultados, pois "nunca haviam feito isso antes e não sabiam expressar por escrito como haviam desenvolvido seu raciocínio" (7.6). Igualmente, houve dificuldades em relação a argumentação oral e, portanto, "as expectativas com relação ao método não foram atingidas no que se refere à expressão oral e escrita" (20.1).

Revelou-se como um obstáculo forte a não inserção da Investigação Matemática em sala de aula, o tempo requerido para a realização das atividades (27.1), para a preparação e elaboração da aula, bem como para a preparação e elaboração das tarefas a serem propostas. A falta de tempo causou o apressamento da aula e, por vezes, até a interrupção do trabalho. O agravamento causado pelo tempo pode ser sentido nas palavras de uma professora, que relata: 
"A questão do tempo se arrastando de uma aula para outra impedindo de se fazer o mais importante, a discussão final e o fechamento das investigações e reflexões incitadas pelas tarefas; o que obriga a, na aula seguinte, resgatá-las, já com boa parte da motivação desvanecida, gastando um tempo grande até que todos se envolvam novamente com a mesma motivação da aula anterior perdendo-se muito em qualidade" (5.6).

A pluralidade e a abertura das tarefas de Investigação Matemática se mostraram obstáculos nas práticas empreendidas, pois "para uma mesma atividade existem várias possibilidades de chegar a uma mesma conclusão, esse parece ser o maior obstáculo à implementação dessa metodologia para o ensino de matemática" (12.8). Além disso, "demanda mais tempo e pode comprometer o desenvolvimento de outros conteúdos matemáticos previstos e que deviam ser trabalhados" (17.13).

O obstáculo relacionado à pluralidade e à abertura das tarefas repousa sobre a justificativa de que a existência de várias possibilidades investigativas em uma mesma tarefa, requer tempo e um conhecimento matemático amplo, o que "pode levar professores inexperientes ou com menor domínio dos conteúdos a evitarem o uso desse tipo de atividades na sala de aula" (12.10). Além disso, as próprias características de leitura, interpretação, produção de relatórios, socialização e discussão dos resultados, inatas da Investigação Matemática, causaram problemas, uma vez que "exigem mais tempo para o planejamento das aulas e, sobretudo, olhar atento do professor e muita organização para que todos os alunos realmente se envolvam nas atividades" (30.4).

\section{A categoria $C_{3}-$ Obstáculos advindos da estrutura escolar}

\section{Unidades de sentido}

A necessidade de se cumprir o currículo, como comentado durante o grupo de trabalho em rede - GTR, também priva, ou até mesmo desestimula iniciativas do professor em tentar caminhos inovadores que altere sua rotina que está pautada em: livro didático - lousa e vice-versa (27.5)

Ao mesmo tempo, foi levantado que a própria estrutura curricular, que elenca muitos conteúdos, dificulta a realização de um trabalho investigativo em sala de aula devido ao pouco tempo direcionado a cada assunto (26.2)

Algumas dificuldades e barreiras foram encontradas no decorrer do processo: o número elevado de alunos em sala de aula (27.6)

Convém também destacar alguns pontos que dificultaram o processo de intervenção, sendo o primeiro deles o perfil da turma: numerosa e com alunos com dificuldades acentuadas de aprendizagem e indisciplina (30.2)

É um grande desafio, pois o sistema tradicional de ensino ainda é predominante nas escolas (29.1)

\section{Unidades de significado}

O cumprimento do currículo escolar é um fator que desestimula e impede a inserção de novas metodologias para o ensino de Matemática em sala de aula.

A estrutura curricular não permite a realização do trabalho investigativo devido à quantidade de conteúdo a serem cumpridos.

A quantidade excessiva de alunos por classe foi uma dificuldade encontrada no trabalho com a Investigação Matemática. As dificuldades acentuadas de aprendizagem foi um fator que impôs dificuldades no trabalho com a Investigação Matemática.

O tradicionalismo de ensino é um desafio a ser superado para a inserção da 


\section{Unidades de sentido}

No entanto, devido a dinâmica da escola, a sucessão de acontecimentos e o ritmo das aulas, foi se tornando difícil apreender, na sua globalidade, o efeito do trabalho realizado pelo projeto nos participantes (5.8)
Unidades de significado

Investigação Matemática na escola.

A dinâmica da escola em sentido lato foi prejudicial ao processo de ensino pautado na Investigação Matemática.

Quadro 4 - Algumas unidades de significado articuladas na categoria C3

Fonte: Elaborado pelo autor (2019)

Esta categoria revela obstáculos emergentes da estrutura e da organização escolar. Dentre eles, está o currículo demasiadamente extenso e o seu cumprimento como uma exigência velada por parte das instituições escolares e sistemas educativos, conforme exprime o excerto: “A necessidade de se cumprir o currículo [...] também priva, ou até mesmo desestimula iniciativas do professor em tentar caminhos inovadores que altere sua rotina que está pautada em: livro didático - lousa e vice-versa" (27.5).

A quantidade elevada dos conteúdos a serem ensinados (26.2) mostrou-se um problema, na medida em que trouxe novamente à tona a questão do tempo, escasso no ambiente escolar, relegando a Investigação Matemática ao status de um trabalho esporádico. Isso fica evidente ao ser relatado que "essa modalidade: investigações matemáticas, deve ser aplicada esporadicamente, pois temos um currículo muito extenso para ser cumprido e parece que esse tipo de trabalho leva mais tempo para ser desenvolvido com os alunos do que o método tradicional" (27.1).

A falta de tempo, imposta pela rotina escolar, privou o professor de elementos importantes do processo de ensino, como, por exemplo, de pesquisar a sua própria prática ou assuntos correlatos à Matemática. De acordo com alguns professores, "todo professor deve ser também um pesquisador, porém a rotina escolar não permite que se faça um estudo aprofundado sobre os diversos assuntos da Matemática" (7.1). Além disso, o excerto (7.1) exprime outros obstáculos inerentes à dinâmica escolar, dentre eles, o enraizamento da Escola nos princípios tradicionais de ensino, a falta da cultura investigativa na execução das atividades de ensino e a falta de apoio familiar na Educação como um todo.

A organização dos horários em geral, fixos e fracionados, em conjunto com o número reduzido de aulas, quebrou a dinâmica da prática investigativa, devendo os obstáculos superados em uma aula, serem novamente superados na aula seguinte, como, por exemplo, o engajamento dos alunos e a retomada das ideias e do ponto de parada da aula anterior. Além disso, "era necessário, às vezes, apressar ou interromper o trabalho" (7.5).

A quantidade excessiva de alunos por turma (27.6) requereu uma maior atenção do professor que desprendeu mais tempo ao atendimento de uns, ausentando-se do atendimento de outros. Tal ausência foi justificada pelo "grande número de alunos que dificultava o 
atendimento a todos os grupos" (7.4). O tempo gasto com o atendimento aos alunos foi potencializado quando o professor se deparou com dificuldades de aprendizagem acentuadas (30.2). Desse modo, o número elevado de alunos aliado a casos de extrema dificuldade de aprendizagem se mostrou um fator que dificultou e prejudicou a orientação individual.

\section{A categoria $\mathrm{C}_{4}$ - Obstáculos advindos da inserção das TIC em aulas de Investigação Matemática}

\section{Unidades de sentido}

A dificuldade para dar início às atividades com os alunos foi o funcionamento precário dos computadores (17.1)

Os objetivos dessa atividade não foram plenamente alcançados. O primeiro obstáculo foi a falta de familiaridade com o software (13.4)

Percebemos que havia dificuldades quanto à utilização do software GeoGebra e que a maioria dos professores preferiram utilizar lápis e papel durante esta atividade (6.2)

A precariedade dos equipamentos do laboratório do PRD na escola de implementação do projeto, dificultou muito a sua aplicação (17.12)

As dificuldades encontradas durante a execução desta atividade de investigação matemática, pela necessidade de usar muitas ferramentas e as respectivas opções para mudar o estilo e a cor das retas mediatrizes, alturas e medianas do triângulo (9.1)

Para conhecer e explorar todo o software seria necessário um tempo muito maior, no entanto, nessa aula, os alunos tiveram apenas noções básicas e muitas dúvidas ainda ficaram. Outro fator que restringiu o melhor aproveitamento da turma foi o número limitado de computadores, pois se observou que o aluno que não estava trabalhando diretamente no programa não se interessava muito no desenvolvimento das atividades propostas (13.2)

Quadro 5 - Algumas unidades de significado articuladas na categoria C4

Fonte: Elaborado pelo autor (2019)

Esta categoria revela os obstáculos relacionados ao uso da TIC em aulas de Investigação Matemática, os quais se mostraram presentes tanto em ordem técnica como em ordem pedagógica. No tocante à ordem técnica, as dificuldades encontradas estão relacionadas "ao funcionamento precário dos computadores" (17.1), à falta de equipamentos, à má estrutura dos laboratórios, à falta de acesso e "a lentidão da internet ou a "trava" dos computadores" (5.10) e ao agendamento de horário.

Os professores relataram que "mesmo após a manutenção dos computadores, não foi possível utilizá-los com a turma, pois o número de equipamentos colocado em funcionamento 
era reduzido (7computadores/28 alunos)" (17.2) e que "a precariedade dos equipamentos do laboratório na escola de implementação do projeto, dificultou muito a sua aplicação" (17.12). Esses problemas técnicos impactaram a prática de ensino de tal modo que o bom aproveitamento das atividades ficou restrito aos alunos que tiveram acesso à máquina, "pois o aluno que não estava trabalhando diretamente no programa não se interessava muito no desenvolvimento das atividades propostas" (13.2).

$\mathrm{Na}$ ordem pedagógica, os obstáculos estão relacionados à falta de habilidade com recursos computacionais, tanto por parte dos professores (6.2) como por parte dos alunos. A construção dos elementos geométricos a serem investigados requereu tempo e o manuseio de diversas ferramentas concomitantemente (9.1), o que fez com que as primeiras aulas fossem destinadas ao ensino das noções básicas do software ou da ferramenta tecnológica utilizada, mas que não foram suficientes para possibilitar o domínio das respectivas funcionalidades, permanecendo muitas dúvidas (13.2).

Ainda, algumas dificuldades técnicas originaram-se do mau uso dos equipamentos, conforme exprime o excerto: "durante a aula anterior, alguém havia "puxado" uns fios e toda uma ilha (esses laboratórios funcionam com quatro telas conectadas a uma mesma CPU), e quatro máquinas sofreram danos" (5.3). Como consequência dessa estrutura, denominada ilha, pode estar a lentidão na rede de internet e o travamento dos computadores, acarretado pelo excesso de fluxo, tanto no processamento como no envio e recebimento de informações.

\section{Articulando o revelado}

Os dados revelam que as dificuldades e os obstáculos, encontrados no trabalho prático com a Investigação Matemática no contexto do PDE, emergem de causas relacionadas aos sujeitos envolvidos (professor e aluno), de causas intrínsecas à perspectiva investigativa, de causas inerentes à organização escolar e da utilização das TIC. As escolas, geralmente, prezavam pelo o cumprimento do currículo, cuja extensão impõe a limitação do tempo para a abordagem de cada conteúdo, mesmo para o método mais retrógrado, o que impôs o aligeiramento e até a interrupção das práticas empreendidas.

Um ambiente estruturalmente fechado, com um currículo já constituído e, por vezes, rígido, se mostra um fator negativo à inserção de novas práticas educativas, na medida em que elas confrontam o sistema educacional vigente, cabendo ao professor romper com essa estrutura ou, pelo menos, flexibilizá-la (CEOLIM; CALDEIRA, 2017). No caso das práticas de Investigação Matemática empreendidas no contexto do PDE, isso ficou evidente. 
No tocante às causas relacionadas aos professores, há razões para supor que elas possuem relações diretas com a sua formação inicial e continuada que, em geral, não contemplaram métodos alternativos de ensino, como por exemplo, a Investigação Matemática. Segundo o relatado por alguns professores, "foi uma formação voltada para uma Matemática de cálculos e respostas corretas" (26.1). Desse modo, mesmo que tenham tido contato com a teoria da Investigação Matemática no PDE, os professores adentraram a sala de aula sem se sentirem preparados para o trabalho com essa perspectiva. Em face disso, há razões para supor que não foi a postura do professor, em si, que se configurou como um obstáculo para o trabalho com essa metodologia, mas, antes, a forma que ele foi/é preparado para esse trabalho. Nesse sentido, há um deslocamento de foco, incidindo agora sobre os processos formativos.

A questão da formação inicial já foi apontada por Ceolim e Caldeira (2015) como um obstáculo para a inserção de metodologias situadas no paradigma investigativo, na Educação Básica, a exemplo da Modelagem Matemática. Segundo estes autores, isso se deve à predominância de disciplinas voltadas aos conteúdos matemáticos no escopo das atividades curriculares dos cursos de Licenciatura em Matemática paranaenses.

Particularizando a Investigação Matemática, os déficits relativos à formação podem ser em partes superados, se houver maior proximidade com a Investigação Matemática, tanto na formação inicial quanto na continuada, ou seja, se houver a presença mais efetiva e constante dessa perspectiva no âmbito das formações. Por ora, parece-me "que pouco tem se avançado em termos práticos, deixando a questão da formação de professores em Investigação Matemática somente na esfera dos discursos, salvaguardadas valorosas exceções" (WICHNOSKI; KLÜBER, 2018, p. 71).

A existência de alguns obstáculos relacionados à inserção das TIC nas aulas de Investigação Matemática, em particular os de ordem pedagógica, podem encontrar explicações na falta de habilidade dos professores com os recursos computacionais, juntamente à falta de planejamento da aula investigativa e virtual. De modo circular, isso aponta novamente para a questão da formação de professores, que deve prepará-lo em face das novas ferramentas tecnológicas e suas especificidades, bem como para o uso adequado destas em prol do ensino.

Sobre isso, Valente (1999, p. 9) nos diz que "não se trata de criar condições para o professor simplesmente dominar o computador ou o software, mas sim auxiliá-lo a desenvolver conhecimento sobre o próprio conteúdo e sobre como o computador pode ser integrado no desenvolvimento desse conteúdo". Segundo os professores participantes do PDE, a superação dos obstáculos impostos pelo uso de softwares em aulas de Investigação Matemática, necessita 
de "um planejamento mais adequado e um tempo maior para a familiarização com o programa e para a resolução das questões propostas" (13.6).

Quanto às causas relacionadas aos alunos, podemos inferir que elas estão diretamente relacionadas aos problemas de formação, em especial, naquelas relativas ao ensino tradicional, aos problemas comportamentais e à aversão à Matemática. Segundo o relatado pelos professores participantes do PDE, a formação escolar dos alunos, em geral, não vinha acontecendo pautada em criticidade, reflexividade e protagonismo, relegando ao professor o trabalho prático de pensamento, de dúvidas e de construção do conhecimento.

Ao longo do tempo, isso enraíza concepções de ensino e aprendizagem contrárias ao que é proposto pela Investigação Matemática, constituindo-se um obstáculo a ser enfrentado. Sobre isso, uma professora explicita que "os alunos têm muita dificuldade com a linguagem matemática tanto para interpretar o que se pede, como para fazer análises e registros dos resultados. Acredito que seja uma questão cultural, passou-se muito tempo valorizando as respostas prontas, onde os professores dão a palavra final sobre os conceitos trabalhados, por isso, utilizando uma metodologia diferenciada leva um tempo para que professores e alunos se adaptem" (17.8).

Historicamente, há certa apatia por parte dos alunos com relação à disciplina de Matemática que, segundo Carmo e Simionato (2012, p. 317), “está diretamente relacionada a experiências inadequadas de ensino dessa disciplina”. Os altos índices de alunos com dificuldades de compreensão dos seus conteúdos a mistificam como uma ciência rigorosa "relacionando-a a algo de difícil apreensão, somente acessível a poucos indivíduos, que exige muito esforço e dedicação para ser dominado" (p. 319).

Desse modo, pode-se inferir que alguns dos obstáculos encontrados nas práticas de Investigação Matemática empreendidas no âmbito do PDE, como por exemplo, os advindos da rejeição e das dificuldades dos alunos com a Matemática, não são exclusividade de práticas de Investigação Matemática. São, antes disso, obstáculos que se mostram presentes no ensino da disciplina em sua amplitude e, em partes, estão diretamente ligados à concepção dos alunos acerca da Matemática, às suas experiências negativas com a disciplina e aos modos como ela é ensinada.

A discrepância entre a Matemática escolar vigente e a Matemática proposta pela Investigação Matemática revelou-se de tal modo significativa, que os alunos, ao trabalharem investigativamente, viram outra Matemática. Para eles, "a atividade proposta parece remeter a outra Matemática, diferente daquela que eles conhecem” (3.7). Essa ilusão de ótica se dá pelo fato de que o que é visto em práticas de Investigação Matemática é o processo de construção e 
não a Matemática em termos de resultados. Isso aponta para a necessidade de conceber uma formação escolar voltada para a reflexividade e desenvolvimento de habilidades que permitam ao aluno questionar, investigar e solucionar problemas dos mais variados tipos e nos mais variados domínios, não necessariamente matemáticos.

As características próprias do trabalho com a perspectiva investigativa, como por exemplo, a abertura das tarefas, as múltiplas possibilidades de investigá-las, a escrita de relatórios, a interpretação, a tomada de decisões, o levantamento de conjecturas e o tempo necessário a esse tipo de trabalho, são aspectos que do ponto de vista epistemológico fazem da Investigação Matemática um método em potencial para o ensino, e do ponto de vista prático mostraram-se problemáticos nas práticas empreendidas no contexto do PDE.

Em face disso, fica o alerta da necessidade de fomentar nos alunos, ao longo da vida escolar, as competências básicas de interpretação, escrita e tomada de decisões, de modo a prepará-los não somente para o período seguinte, mas para a vida; e um modo de suscitá-las é por meio de tarefas abertas que requerem inquirições e que permitam aos alunos comunicar sobre a Matemática e por meio dela. Tal necessidade já foi alertada por Silva et al. (1999) ao mencionarem que

[...] a prática de muitos professores de Matemática ainda não assenta em pressupostos metodológicos de integração de atitudes, capacidades e conhecimentos ou em preocupações de estabelecimento de conexões matemáticas ou na abordagem em espiral dos conceitos ou na concepção de tarefas que possibilitem aos alunos fazer matemática e desenvolverem o seu poder matemático (SILVA et al., 1999, p. 7).

Para o trabalho com a Investigação Matemática é fundamental que as ações sejam realizadas pelos alunos, conforme reconhece um professor participante do PDE ao relatar que "para utilizar essa metodologia, [...] é fundamental que o trabalho seja desenvolvido pelos alunos" (27.14), porém o mesmo professor adverte que "eles não têm a prática de serem os protagonistas na sala de aula, pois em geral é o professor que exerce essa função" (27.14). Isso sugere que os papeis do professor e do aluno durante as aulas, comumente, estão bem definidos, de modo que o professor sente segurança e o aluno sente comodidade nas atividades realizadas. Fica atribuído ao professor desempenhar esforços cognitivos de compreensão, exploração e resolução das tarefas, ficando o aluno, na condição de sujeito passivo, fazendo meras anotações.

Essa configuração dos papeis do professor e dos alunos pode encontrar explicações na cultura escolar vigente e que tem permanecido em nosso país. De acordo com Wichnoski e Klüber (2017, p. 173), esse "é, se não o maior, um dos principais fatores que entrava e, por vezes, não permite a inserção de novas metodologias para o ensino de matemática no ambiente escolar”. Herança de uma tendência positivista, a Escola brasileira contemporânea ainda não 
conseguiu se desprender das amarras behavioristas da aprendizagem, pautando o ensino, em particular de Matemática, na objetividade do conhecimento e em métodos instrumentalistas, resultando em "uma educação escolar [...] sustentada nos princípios de uma visão da matemática como um corpo acabado de conhecimentos, de uma aula onde o professor, único detentor da verdade, repete para os alunos uma matemática pronta e decorada" (12.9).

Isso exprime a configuração do processo de ensino de Matemática mais presente nas Escolas, o qual repousa sobre uma estrutura consolidada de conteúdos e exercícios, de modo que a Matemática é apresentada como um corpo de conhecimentos absoluto e a-histórico. Há apenas uma instrumentalização de métodos e técnicas, como se a Matemática fosse um jogo que privilegia o indivíduo com maior capacidade de memorização das suas regras.

Há razões para supor que essa cultura também justifica a dificuldade que os alunos mostraram ter com a linguagem matemática e com a atividade matemática genuína de pensar, conjecturar e concluir, bem como justifica a falta de envolvimento com as atividades propostas. Conforme já mencionado, em geral, o aluno ocupa uma posição passiva no processo de ensino e aprendizagem e isso faz com que os esforços cognitivos a serem empreendidos em face do novo conhecimento sejam minimizados e, por vezes, tolhidos. Ao passo que são convidados a pensar e a esforçarem-se cognitivamente por meio do trabalho investigativo, há a existência de dificuldades e resistência.

Por cultura, entendo-a, segundo Levi-Strauss (1976 apud MELLO, 1986, p. 397), como um "conjunto complexo que inclui conhecimento, crença, arte, lei, costumes e várias outras aptidões e hábitos adquiridos pelo homem como membro de uma sociedade". A Educação, enquanto prática social, possui uma dimensão cultural e é alcançada por este conjunto. As concepções e crenças, enquanto produtos socioculturais, apontam caminhos, sustentam decisões e influenciam a prática docente (TARDIF, 2002; PONTE, 1992) e, a meu ver, se ampliam, influenciando a prática discente, a prática de gestão escolar, a prática da equipe pedagógica, bem como as ações da família e do Estado.

A concepção dominante de Educação concebe o ensino amparado no planejamento e na técnica, na obediência à legislação, na divisão do trabalho pedagógico entre os que pensam e os que fazem, na rigidez do controle burocrático e na prevalência da razão técnica (GADOTTI, 1995), notadamente características da tendência positivista. Sob a égide dessa concepção, salvaguardadas valorosas exceções, estão professores, alunos, equipe pedagógica, família dos estudantes e todos aqueles envolvidos com o sistema educativo. Nesse sentido, a prática de ensino pautada na Investigação Matemática acontece sob uma cultura contrária a ela, o que, por si só, é um obstáculo. 


\section{Referências}

BICUDO, M. A. V. Aspectos da pesquisa Qualitativa efetuada em uma abordagem fenomenológica. In: BICUDO, M. A. V. (org.). Pesquisa qualitativa segundo a visão fenomenológica. São Paulo: Cortez, 2011, p. 29-40.

BRUYNe, P.; HeRMAN, J.; SCHOUTHEete, M. Dinâmica da Pesquisa em Ciências Sociais: os polos da pratica metodológica. Tradução Ruth Joffily. Rio de Janeiro: F. Alves, 1977.

CARMO, J. S.; SIMIONATO, A. M. Reversão de ansiedade à Matemática: alguns dados da literatura. Psicologia em Estudo, Maringá, v. 17, n. 2, p. 317-327, abr./jun. 2012.

CEOLIM, A. J; CALDEIRA, A. D. Obstáculos e Dificuldades Apresentados por Professores de Matemática Recém-Formados ao Utilizarem Modelagem Matemática em suas Aulas na Educação Básica. Bolema, Rio Claro, v. 31, n. 58, p. 760-776, ago. 2017.

. Modelagem Matemática na Educação Matemática: obstáculos segundo professores da Educação Básica. Educação Matemática em Revista - SBEM, n. 46, p. 25-34, 2015.

CUNHA, M. H. Dilemas e Dificuldades de Professores de Matemática. Millenium, n. 20, out. 2000.

GADOTTI, M. Educação e compromisso. 5. ed. Campinas: Papirus, 1995.

HUSSERL, E. Ideias para uma fenomenologia pura e para uma filosofia fenomenológica. Aparecida: Ideias e Letras, 2006.

A crise da humanidade europeia e a filosofia. Introdução e Tradução Urbano Zilles. 2. ed. Porto Alegre: EDIPUCRS, 2002.

MARTINS, J.; BICUDO, M. A. V. A pesquisa qualitativa em Psicologia: fundamentos e recursos básicos. São Paulo: Educ/Moraes, 1989.

MELLO, L. G. Antropologia Cultural. Petrópolis: Vozes, 1986.

MINAYO, M. C. S. (org.). Pesquisa Social: Teoria, método e criatividade. 18. ed. Petrópolis: Vozes, 2001.

MONDINI, F.; MACROSKY, L. F.; BICUDO, M. A. V. A Hermenêutica em Educação Matemática: Compreensões e Possibilidades. REVEMAT, Florianópolis, v. 11, p. 317-327, 2016.

PARANÁ. Lei Complementar $\mathbf{n}^{0}$ 130, de 14 de julho de 2010. Diário Oficial do Paraná, Poder Executivo, Paraná, PR, 2010.

PEREIRA, J. M. História da Matemática na Formação do Professor: dificuldades e sugestões. 2013. Dissertação (Mestrado em Ensino de Matemática) - Universidade Federal do Rio Grande do Norte, Natal, 2013.

PONTE, J. P. Concepções dos professores de matemática e processos de formação. In: PONTE, J. P. (ed.) Educação Matemática: Temas de investigação. Lisboa: Editora, 1992. p. 185-239.

PONTE, J. P.; BROCARDO, J.; OLIVEIRA, H. Investigações Matemáticas na Sala de Aula. Belo Horizonte: Autêntica, 2013.

SILTRÃO; K. S.; CRISTOVÃO, E. M. Investigação Matemática: Dificuldades Encontradas por uma Professora Iniciante. Cadernos da Pedagogia, São Carlos, v. 4, n. 7, p. 125 -134, jan./jun. 2010. 
SILVA, A.; VELOSO, E.; PORFÍRIO, J.; ABRANTES, P. O currículo de matemática e as actividades de investigação. In ABRANTES, P.; PONTE, J. P.; FONSECA, H.; BRUNHEIRA, L. (org.), Investigações matemáticas na aula e no currículo. Lisboa: APM e Projecto MPT, p. 69-88, 1999.

SOKOLOWSKI, R. Introdução à fenomenologia. Tradução Alfredo de Oliveira Moraes. 3. ed. São Paulo: Loyola, 2012.

TARDIF, M. Saberes docentes e formação profissional. Petrópolis: Vozes, 2002.

VALENTE, J. A. (org.). O computador na sociedade do conhecimento. Campinas: Central da UNICAMP/NIED, 1999.

WICHNOSKI, P.; KLÜBER. Investigações Matemáticas na Educação Matemática: uma experiência na formação inicial de professores. Revista de Educação Matemática, São Paulo, v. 15, n. 18, p. 6983, jan. /abr. 2018.

. Considerações sobre práticas de Investigação Matemática empreendidas e relatadas por professores em formação. RPEM, Campo Mourão, v. 6, n. 11, p. 161-178, jul.-dez. 2017.

Submetido em 24 de Maio de 2019 Aprovado em 27 de Janeiro de 2020 
Anexos

Título do trabalho e link de acesso

$\mathrm{O}$ ensino da matemática na perspectiva das metodologias propostas nas diretrizes curriculares do Paraná

http://www.diaadiaeducacao.pr.gov.br/portals/pde/arquivos/716-4.pdf

A TV Multimídia, um Objeto de Aprendizagem para a Educação Matemática, Significados e Discussões

http://www.diaadiaeducacao.pr.gov.br/portals/cadernospde/pdebusca/producoes_pde/ 2008 ufpr_mat_artigo_dolores_follador.pdf

Possibilidades de investigações matemáticas relacionadas ao número e a proporção áurea

http://www.diaadiaeducacao.pr.gov.br/portals/cadernospde/pdebusca/producoes pde/ 2008 unioeste mat artigo arleni elise sella.pdf

Experiências com probabilidade e estatística no ensino médio

http://www.diaadiaeducacao.pr.gov.br/portals/cadernospde/pdebusca/producoes pde/

2008 uel mat artigo rachel santos borges david.pdf

Relação cognição e afetividade na aprendizagem da matemática

http://www.diaadiaeducacao.pr.gov.br/portals/cadernospde/pdebusca/producoes_pde/ 2008 ufpr_mat_artigo_luciana_roder.pdf

O uso do material dourado no ensino aprendizagem dos produtos notáveis na $7^{\mathrm{a}}$ série http://www.diaadiaeducacao.pr.gov.br/portals/cadernospde/pdebusca/producoes_pde/ 2009 utfpr_matematica_artigo_marilda terezinha_de_oliveira.pdf

Aplicação da Investigação Matemática em números naturais http://www.diaadiaeducacao.pr.gov.br/portals/cadernospde/pdebusca/producoes_pde/ 2009 uel_matematica_artigo_maria_aparecida_semeghini_bernard.pdf

Investigação Matemática como alternativa metodológica para superação de problemas nas operações fundamentais

http://www.diaadiaeducacao.pr.gov.br/portals/cadernospde/pdebusca/producoes pde/ 2009 unicentro matematica artigo rosemeri fillus chuproski.pdf

Estudo do software educativo de matemática GeoGebra para aplicação na investigação dos Conteúdos estruturantes: funções e geometria

http://www.diaadiaeducacao.pr.gov.br/portals/cadernospde/pdebusca/producoes_pde/ 2009 uel_matematica_artigo_nunciata_carboni_da_costa.pdf

A Investigação Matemática e o conceito de funções: um estudo com alunos da $8^{\text {a }}$ série do ensino fundamental

http://www.diaadiaeducacao.pr.gov.br/portals/cadernospde/pdebusca/producoes pde/ 2009 uel matematica_artigo_sandra maria pimenta ferreira.pdf

Investigação Matemática: as embalagens e o estudo de geometria

http://www.diaadiaeducacao.pr.gov.br/portals/cadernospde/pdebusca/producoes pde/ 2009 uel matematica_artigo_sandra_mara mantovani.pdf

O desenvolvimento do pensamento algébrico por meio de investigações em sala de aula

http://www.diaadiaeducacao.pr.gov.br/portals/cadernospde/pdebusca/producoes pde/ 2009 uel matematica artigo elisangela cristina perugini maza.pdf

Investigação Matemática: uma nova perspectiva para o ensino e a aprendizagem da geometria

http://www.diaadiaeducacao.pr.gov.br/portals/cadernospde/pdebusca/producoes_pde/ 2009 unioeste_matematica_artigo_clecimara_da_silva_medeiros.pdf

Investigações Matemáticas em sala de aula com o GeoGebra

http://www.diaadiaeducacao.pr.gov.br/portals/cadernospde/pdebusca/producoes pde/ 2009 fecilcam_matematica_artigo_carmem_lucia_dionisio_rocha_pdf

Investigação matemática: uma proposta metodológica para o ensino de fractais construídos através do software GeoGebra

http://www.diaadiaeducacao.pr.gov.br/portals/cadernospde/pdebusca/producoes pde/ 2009 unicentro matematica artigo claudia tratch.pdf
Autores

Arilda Maria Passos

Luiz Amilton de Góes

Dolores Follador

Arleni Elise Sella

Patrícia Sandalo

Pereira

Rachel Santos Borges

David

Ana Lucia da Silva

Luciana Röder

Tânia T. Bruns Zimer

Marilda Terezinha de

Oliveira Roik

Vitor José Petry

Maria Aparecida

Semeghini

Bernardelli

Túlio Oliveira de

Carvalho

Rosemeri

Chuproski

Lucas de Oliveira

Nunciata Carboni da

Costa

Sandra Malta Barbosa

Sandra Maria

Pimenta Ferreira

Magna Natalia Marin

Pires

Sandra Mara

Mantovani

Magna Natalia Marin

Pires

Elisangela Cristina

Perugini Mazaro

Magna Natalia Marin

Pires

Clecimara da Silva

Medeiros

Arleni Elise Sella

Carmem Lucia
Dionisio Rocha
Navasconi
Wellington Hermann
Cláudia Tratch
Leoni Malinoski
Fillos


Explorando Conceitos Geométricos Por Meio Do Geogebra: quatro momentos de investigações matemáticas no $9^{\circ}$ ano do Ensino Fundamental

http://www.diaadiaeducacao.pr.gov.br/portals/cadernospde/pdebusca/producoes pde/ 2010/2010 unicentro mat artigo maria ines tomal_surmas.pdf

Tarefas de investigação para o ensino-aprendizagem das propriedades de divisibilidade dos números naturais

http://www.diaadiaeducacao.pr.gov.br/portals/cadernospde/pdebusca/producoes_pde/ 2010/2010_uel mat_artigo conceicao_geni_nicoli.pdf

$\mathrm{O}$ ensino de geometria plana no ensino fundamental: tarefas investigativas utilizando o software GeoGebra

http://www.diaadiaeducacao.pr.gov.br/portals/cadernospde/pdebusca/producoes pde/ 2010/2010 uel mat artigo rejana mara ribeiro.pdf

Conjuntos numéricos, com ênfase nos números inteiros

http://www.diaadiaeducacao.pr.gov.br/portals/cadernospde/pdebusca/producoes_pde/ 2010/2010_uel_mat_artigo_catarina_ferreira.pdf

Investigações Matemáticas: Uma Abordagem aos Professores da Rede Pública do Estado do Paraná

http://www.diaadiaeducacao.pr.gov.br/portals/cadernospde/pdebusca/producoes pde/ 2010/2010 utfpr mat artigo margarete kolczycki borges.pdf

Tarefas Investigativas e o Desenvolvimento do Pensamento Algébrico: Uma Experiência com Alunos de $7^{\circ}$ Ano

http://www.diaadiaeducacao.pr.gov.br/portals/cadernospde/pdebusca/producoes_pde/ 2012/2012 uel mat artigo sonia terezinha sgobero abudi.pdf

Investigação matemática na perspectiva de ampliar a participação e contribuir no ensino-aprendizagem das operações através da problematização

http://www.diaadiaeducacao.pr.gov.br/portals/cadernospde/pdebusca/producoes_pde/ 2012/2012_unicentro_mat_artigo_marinez_suely_de_goes_stipp.pdf

O ensino de geometria por meio do GeoGebra e de Investigações Matemáticas http://www.diaadiaeducacao.pr.gov.br/portals/cadernospde/pdebusca/producoes_pde/ 2012/2012_unicentro_mat_artigo_rosangela_andrechovicz.pdf

Atividades Investigativas de Matemática: uma experiência com alunos do $6^{\circ}$ ano do ensino fundamental

http://www.diaadiaeducacao.pr.gov.br/portals/cadernospde/pdebusca/producoes pde/ 2012/2012 uem mat artigo lucia helena de araujo.pdf

Aulas investigativas no ensino da álgebra no $8^{\circ}$ ano

http://www.diaadiaeducacao.pr.gov.br/portals/cadernospde/pdebusca/producoes_pde/ 2012/2012_unicentro_mat_artigo_regiane_gomes_de_araujo.pdf

Investigação Matemática: Um Enfoque aos Conteúdos Geométricos

http://www.diaadiaeducacao.pr.gov.br/portals/cadernospde/pdebusca/producoes pde/ 2012/2012_unioeste_mat_artigo_tavania_suzer_da_silva.pdf

Investigação Matemática: Curso de Formação para professores na cidade de SarandiPR

http://www.diaadiaeducacao.pr.gov.br/portals/cadernospde/pdebusca/producoes pde/ 2012/2012 uem mat artigo cleide miguel da cruz.pdf

Investigações Matemáticas: possibilidades para o trabalho com funções por meio do GeoGebra

http://www.diaadiaeducacao.pr.gov.br/portals/cadernospde/pdebusca/producoes pde/ 2012/2012 fecilcam mat artigo reinaldo gomes.pdf

Tarefas de Investigação Matemática numa Trajetória de Ensino e Aprendizagem http://www.diaadiaeducacao.pr.gov.br/portals/cadernospde/pdebusca/producoes_pde/ 2012/2012_uel_mat_artigo_janete_guiraldeli_lenartovicz.pdf

Jogos e Investigação Matemática numa Trajetória de Ensino e Aprendizagem http://www.diaadiaeducacao.pr.gov.br/portals/cadernospde/pdebusca/producoes_pde/ 2012/2012_uel_mat_artigo_jose_mario_lenartovicz.pdf
Maria Inês Tomal Surmas

Leoni Malinoski

Fillos

Conceição Geni

Nicoli

Túlio Oliveira de Carvalho

Rejana Mara Ribeiro

Sandra Malta Barbosa

Catarina Ferreira

Túlio Oliveira de Carvalho

Margarete Kolczycki Borges

Luiz Claudio Pereira

Sonia Terezinha Sgobero Abudi

Magna Natalia Marin Pires

Marinez Suely de Goes Stipp

Soliane Moreira

Rosangela

Andrechovicz

Leoni Malinoski

Fillos

Lucia Helena de

Araujo

Valdeni Soliani

Franco

Regiane Gomes de Araujo

Leoni Malinoski

Fillos

Tavania Suzer da Silva Becker

Dulcyene Maria

Ribeiro

Cleide Miguel da Cruz

Lilian Akemi Kato

Reinaldo Gomes Wellington Hermann

Janete Guiraldeli Lenartovicz

Magna Natalia Marin Pires

José Mario

Lenartovicz

Magna Natalia Marin Pires 
ISSN 1980-4415

Áreas e perímetros: uma abordagem Significativa

http://www.diaadiaeducacao.pr.gov.br/portals/cadernospde/pdebusca/producoes pde/ $\underline{2012 / 2012 \text { uem mat artigo marise ozieranski.pdf }}$

Investigando geometricamente o Tangram utilizando o software GeoGebra http://www.diaadiaeducacao.pr.gov.br/portals/cadernospde/pdebusca/producoes_pde/ 2012/2012_uel_mat_artigo_mara_lucia_rodrigues.pdf

Marise Ozieranski

João Cesar Guirado

Investigações matemáticas no cotidiano do aluno: Um relato de Experiência

http://www.diaadiaeducacao.pr.gov.br/portals/cadernospde/pdebusca/producoes pde/

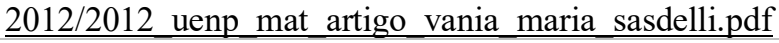

Mara

Lúcia

Rodrigues

Sandra Malta Barbosa

Vânia Maria Sasdelli

George Francisco

Quadro 6 - Identificação dos trabalhos analisados

Santiago Martin

Fonte: Elaborado pelo autor (2019) 